\title{
Overexpression of DUF538 from Wild Arachis Enhances Plant Resistance to Meloidogyne spp.
}

\author{
Ana Claudia Guerra Araujo ${ }^{1}$, Patricia Messenberg Guimaraes ${ }^{1}$, Ana Paula Zotta Mota ${ }^{1}$, \\ Larissa Arrais Guimaraes ${ }^{1}$, Bruna Medeiros Pereira ${ }^{1}$, Christina Cleo Vinson ${ }^{1,2}$, Ana Luíza Lacerda ${ }^{1}$, \\ Andressa Cunha Quintana Martins ${ }^{1}$ and Ana Cristina Miranda Brasileiro ${ }^{1, *}$ \\ 1 EMBRAPA Recursos Genéticos e Biotecnologia, Brasília 70770-917, Brazil; \\ ana-claudia.guerra@embrapa.br (A.C.G.A.); patricia.guimaraes@embrapa.br (P.M.G.); \\ anazottamota@gmail.com (A.P.Z.M.); larissaarrais@gmail.com (L.A.G.); bruagro6@gmail.com (B.M.P.); \\ ccvinson@gmail.com (C.C.V.); analuiza.lacerda@gmail.com (A.L.L.); andressa.cqm@gmail.com (A.C.Q.M.) \\ 2 Departamento de Botânica, Campus Darcy Ribeiro, Universidade de Brasília, Brasília 70910-900, Brazil \\ * Correspondence: ana.brasileiro@embrapa.br
}

check for

updates

Citation: Araujo, A.C.G.; Guimaraes, P.M.; Mota, A.P.Z.; Guimaraes, L.A.; Pereira, B.M.; Vinson, C.C.; Lacerda, A.L.; Martins, A.C.Q.; Brasileiro, A.C.M. Overexpression of DUF538 from Wild Arachis Enhances Plant Resistance to Meloidogyne spp. Agronomy 2021, 11, 559. https:// doi.org/10.3390/agronomy11030559

Academic Editor: Soraya Leal-Bertioli

Received: 19 December 2020

Accepted: 27 February 2021

Published: 16 March 2021

Publisher's Note: MDPI stays neutra with regard to jurisdictional claims in published maps and institutional affiliations.

Copyright: (C) 2021 by the authors Licensee MDPI, Basel, Switzerland. This article is an open access article distributed under the terms and conditions of the Creative Commons Attribution (CC BY) license (https:// creativecommons.org/licenses/by/ $4.0 /)$.
Abstract: DUF538 proteins belong to a large group of uncharacterized protein families sharing the highly conserved Domain of Unknown Function (DUF). Attention has been given to DUF538 domaincontaining proteins due to changes in their gene expression behavior and protein abundance during plant development and responses to stress. Putative roles attributed to DUF538 in plants under abiotic and biotic constraints include involvement in cell redox balance, chlorophyll breakdown and pectin degradation. Our previous transcriptome studies suggested that DUF538 is also involved in the resistance responses of wild Arachis species against the highly hazardous root-knot nematodes (RKNs). To clarify the role of the AsDUF538 gene from the wild peanut relative Arachis stenosperma in this interaction, we analyzed the effect of its overexpression on RKN infection in peanut and soybean hairy roots and Arabidopsis transgenic plants. AsDUF538 overexpression significantly reduced the infection in all three heterologous plant systems against their respective RKN counterparts. The distribution of AsDUF538 transcripts in RKN-infected Arachis roots and the effects of AsDUF538 overexpression on hormonal pathways and redox system in transgenic Arabidopsis were also evaluated. This is the first time that a DUF538 gene is functionally validated in transgenic plants and the earliest report on its role in plant defense against RKNs.

Keywords: Meloidogyne spp.; RKN resistance; hairy roots; peanut; soybean; Arabidopsis; in situ hybridization

\section{Introduction}

The DUF (Domain of Unknown Function) family comprises proteins with one or more conserved domains with no functional annotation. In the Pfam database, more than 4000 DUF families are described, encompassing more than $22 \%$ of the entire database (Pfam 33.2, June 2020, 18,259 entries). Despite DUFs having as yet no clarified function, recent studies suggest that they might play an important role in plant stress responses [1-3]. Within this large family, DUF538 superfamily members are among the most studied proteins, found in more than 40 plant species, almost exclusively in Embryophyta [4]. Changes in DUF538 gene expression behavior and protein abundance were observed during different plant developmental and reproductive stages [5-7] and in response to various abiotic stresses, including drought [8]; high temperature [9]; carbohydrate deprivation [10]; and nitrogen toxicity [11]. DUF538 protein was also reported to be involved in intracellular transport of cuticular waxes, affecting leaf surface permeability and water loss control [12].

Regarding biotic stresses, some reports identified DUF538 transcripts or proteins in response to infection by fungal pathogens [13-16], where they seem to be important activators of the plant antioxidative system and a common component in the responses of 
different stress-challenged plants [17-19]. Additionally, a study of grapevine (Vitis vinifera) showed that genes encoding sugar transporters containing a DUF538 domain, such as SWEET17 proteins, are significantly upregulated in leaves infected with phytoplasma [20]. Our group was the first to describe the involvement of DUF538 in nematode infection using EST sequencing [21], which was further corroborated by distinct approaches for gene expression analysis, such as macro-array [22], qRT-PCR analysis [23] and RNA-seq data $[24,25]$. These studies demonstrated that DUF538 gene expression is induced in the nematode resistant wild peanut (Arachis hypogaea) relative A. stenosperma during its incompatible interaction with the root-knot nematode (RKN) Meloidogyne arenaria.

The most structurally studied plant proteins containing a DUF538 domain are from Celosia cristata, which show partial structural homology to BPI (bactericidal/permeability increasing) proteins of the mammalian innate immune system [17]. DUF538 domaincontaining proteins from C. cristata also exhibited a binding capacity and esterase-type hydrolytic activity towards bacterial lipopolysaccharides and chlorophyll molecules $[19,26,27]$ and a methylesterase activity towards pectin molecules [28], suggesting a probable cooperation between DUF538 and pectin methylesterase protein families in cell wall-associated defense responses in plants.

The increase of redox enzyme activities, including catalase, peroxidase, polyphenol oxidase and phenylalanine ammonia lyase after exogenous application of DUF538 in tobacco (Nicotiana tabacum) leaves [18] and the ubiquity of DUF538 in responses to several types of stress, in different plant species, suggest its association with proteins participating in front line of host defense [8]. This putative involvement of DUF538 in antioxidant activities is reinforced by its upregulation during the hypersensitive response (HR), characterized by the generation of reactive oxygen species (ROS), in the RKN-resistant $A$. stenosperma against $M$. arenaria [29].

Over the years, A. stenosperma, endemic to the southeast region of Brazil, has been exploited as a source of resistance alleles against Meloidogyne spp. [30], being used in breeding programs for introgression of a new source of nematode resistance in peanut [31,32]. Moreover, functional genomics also profited from this resource through transcriptomic and proteomic studies that led to the identification of $A$. stenosperma genes related to nematode resistance $[25,30,33,34]$.

In the present study, for the first time, we functionally validated the role of a DUF538 gene in transgenic plants and evaluated its effect against plant RKNs, one of the most damaging phytoparasites worldwide. To do so, the DUF538 gene was isolated from A. stenosperma (AsDUF538), and the temporal and spatial distribution of AsDUF538 transcripts was identified in roots of susceptible and resistant Arachis species challenged with M. arenaria. Furthermore, AsDUF538 was overexpressed in hairy roots from susceptible genotypes of peanut and soybean (Glycine max) and in transgenic Arabidopsis thaliana plants to evaluate its effect on nematode infection. The expression behavior of the stressmarker genes in Arabidopsis transgenic lines was also analyzed to identify the key defense components triggered by AsDUF538 overexpression.

This study provided more evidence of the role of DUF538 in the plant biotic stress responses and identified a valuable biotechnological asset for the development of crops with improved resistance against RKNs.

\section{Materials and Methods}

\subsection{Characterization and Cloning of AsDUF538}

The complete coding sequence of the AsDUF538 gene from Arachis stenosperma (accession V10309) was identified based on alignments of EH045758.1 (Genbank; [21]) and putative DUF538-domain coding sequences from Arachis species available from NCBI (http:/ /www.ncbi.nlm.nih.gov/; accessed on 10 October 2020) and PeanutBase (https: / / peanutbase.org/; accessed on 10 October 2020), as well as from our previous transcriptome surveys (NCBI BioProject PRJNA284674). Transcript sequences were aligned using the default parameters of the MultAlin tool (http:/ / multalin.toulouse.inra.fr/multalin/; ac- 
cessed on 3 November 2020). The isoelectric point and molecular weight of the AsDUF538deduced protein were predicted using software available at ExPASy (http:/ / expasy.org/; accessed on 10 October 2020). The amino acids alignment and maximum likelihood phylogenetic tree were produced by MEGA X [35].

The $414 \mathrm{bp}$ consensus coding sequence of AsDUF538 (Figure 1A) was synthesized and cloned by Epoch Life Science Inc. (Missouri City, TX, USA), under the control of the Arabidopsis actin 2 promoter and Agrobacterium nopaline synthase terminator, in the binary vector pPZP_201BK_EGFP [36]. The obtained pPZP-AsDUF538 vector comprises two additional cassettes for constitutive expression of the enhanced green fluorescent protein (eGFP) reporter gene and the hygromycin phosphotransferase (hpt) gene coding for hygromycin resistance as the selectable marker [36].
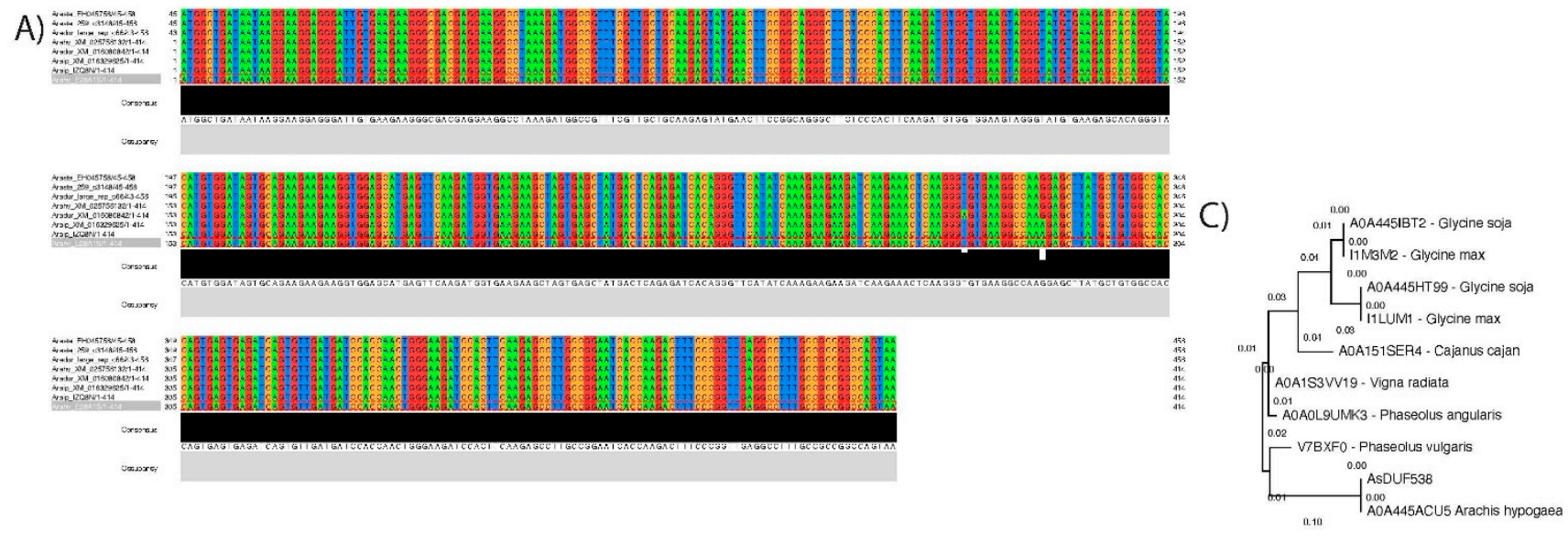

$\mapsto$

0.020

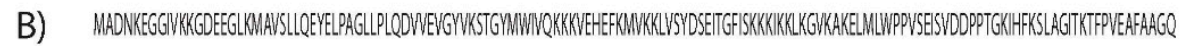

\section{DUF538}

Figure 1. Molecular characterization of AsDUF538. (A) Alignment of the Arachis spp. coding sequences of DUF538 and their consensus nucleotide sequence. (B) Deduced amino acids sequence and the location of DUF538 conserved domain. (C) Maximum likelihood phylogenetic tree.

The pPZP-AsDUF538 and the corresponding empty pPZP_201BK_EGFP (hereafter called pPZP-empty) binary vectors were then introduced into the Agrobacterium rhizogenes pathogenic strain 'K599' and into the disarmed A. tumefaciens strain 'GV3101' using a standard electroporation protocol. Transformed colonies were selected by PCR using specific primer pairs (5'-3') from AsDUF538 (GAGCACAGGGTACATGTGGA/CATAAGCTCCTTGGCCTTCA) or eGFP (CGTCGCCGTCCAGCTCGACCAG/CATGGTCCTGCTGGAGTTCGTG) sequences, according to $[23,37]$, respectively.

\subsection{Nematode Inoculum}

Nematodes were multiplied for three months on greenhouse-grown tomato (Solanum lycopersicum 'Santa Clara') plants. Eggs of Meloidogyne spp. were extracted from roots using $1 \%(v / v) \mathrm{NaOCl}$ and second-stage juveniles (J2) collected from the root and egg suspension, as previously described [29]. Eggs or freshly hatched J2s were collected by centrifugation and quantified under a light microscope using Peters' slides.

\subsection{AsDUF538 Transcripts Distribution in Arachis spp. Roots Inoculated with Meloidogyne arenaria}

For in situ hybridization analysis, the AsDUF538 coding sequence flanked by T7 and SP6 RNA polymerase promoters was cloned into the expression vector pGEM-T-Easy 
(Promega, Madison, WI, USA) and used as a template for in vitro transcription using the DIG RNA Labeling Kit SP6/T7 (Roche, Indianapolis, Indianapolis, USA) to produce both, the antisense (SP6) and sense (T7) digoxigenin-labeled RNA probes. Sections of leaves and roots from eight-week-old plants of the RKN-resistant $A$. stenosperma and susceptible peanut 'Runner IAC-866' were inoculated with 10,000 J2 of M. arenaria. Control plants were mock inoculated. Root samples were collected at three and six DAI (Days After Inoculation) and used to determine the temporal and spatial distribution of AsDUF538 transcripts. Roots were fixed, dehydrated and embedded in BMM (butyl acrylate-methyl methacrylate polymer) plastic resin. Semi-thin sections were obtained and hybridized either with antisense or sense probe for $16 \mathrm{~h}$ at $42{ }^{\circ} \mathrm{C}$. Hybridization sites were immunocytochemically detected, as previously described [23]. Root sections, not counterstained, were observed in the AxioPhot epifluorescence microscope (Zeiss, Oberkochen, Germany) and images captured by the AxioCam MRc digital camera and the corresponding Axiovision Rel. 4.8 software (Zeiss, Oberkochen, Germany).

\subsection{Peanut and Soybean Hairy Roots Inoculation with Meloidogyne arenaria and Meloidogyne javanica}

A. rhizogenes strain 'K599' harboring pPZP-AsDUF538 and pPZP-empty vectors were used to generate hairy roots from both detached leaves of the RKN-susceptible peanut 'Runner IAC-866' and composite plants of the RKN-susceptible soybean 'Williams 82'.

Peanut hairy roots were produced by the ex vitro detached leaf method previously established by our group [37,38], which uses the youngest expanded quadrifoliate leaves harvested from one-month-old peanut plants grown under growth chamber conditions (25 $\pm 2{ }^{\circ} \mathrm{C} ; 12 \mathrm{~h}$ photoperiod; $120 \mu \mathrm{mols} \cdot \mathrm{m}^{-2} \cdot \mathrm{s}^{-1}$ light intensity). Detached leaves were inoculated with $A$. rhizogenes bacterial paste and maintained under moist conditions for approximately 20 days until the emergence of the first hairy roots, essentially as described by $[37,38]$. Transformed hairy roots were individually screened by the presence of GFP fluorescence using a fluorescence stereomicroscope M205 (Leica Microsystems, Wetzlar, Germany) with the GFP1 filter, and roots lacking fluorescence were removed. Detached leaves containing eGFP-positive roots were kept in the growth chamber for 10 additional days and re-evaluated for GFP fluorescence. The eGFP-negative roots were removed and only the detached leaves with eGFP-positive roots, achieving up to $5 \mathrm{~cm}$ in length, as previously established by [38], were used for nematode inoculation. Detached leaves containing only eGFP-positive hairy roots were then transferred to wet vermiculite (grade 3), challenged with $1000 \mathrm{~J} 2$ of $M$. arenaria, and maintained in the growth chamber.

Composite soybean plants were generated by the inoculation of a fresh $A$. rhizogenes paste at the hypocotyl region of four-day-old seedlings, essentially as described by [39]. Hairy roots were selected one week after $A$. rhizogenes transformation through GFP fluorescence, as described above, and the eGFP-negative roots were removed. Composite plants containing only eGFP-positive hairy roots were transferred to a sand: plant gel mixture (3:1; $v: v)$ and acclimated to greenhouse conditions. Hairy roots from three-week-old soybean composite plants transformed with pPZP-AsDUF538 or pPZP-empty were then challenged with $1000 \mathrm{~J} 2$ of $M$. javanica.

At 60 DAI, hairy roots from peanut detached leaves and composite soybean plants were collected, weighted and reevaluated for GFP fluorescence. The nematode infection in hairy roots transformed with both pPZP-AsDUF538 and pPZP-empty vectors was determined by counting the number of galls and egg masses and statistically tested according to [37].

\subsection{Arabidopsis Transformation and OE Lines Selection}

Wild type (WT) Arabidopsis thaliana plants (ecotype Col-0) were transformed with A. tumefaciens 'GV3101' harboring the pPZP-AsDUF538 vector via the floral dip method [40]. Plants were maintained in a controlled growth chamber $\left(21 \pm 2{ }^{\circ} \mathrm{C} ; 12 \mathrm{~h}\right.$ photoperiod; $120 \mu \mathrm{mols} \cdot \mathrm{m}^{-2} \cdot \mathrm{s}^{-1}$ light intensity). T0 transformants were selected on MS agar medium containing $20 \mathrm{mg} / \mathrm{L}$ hygromycin and screened by the presence of GFP fluorescence, as 
described above. Hygromycin-resistant and eGFP-positive T0 plants were transplanted to soil-containing pots and maintained in the growth chamber to produce transgenic AsDUF538 plants at T1 generation. Transformants were then screened repeatedly for hygromycin resistance, as previously described [41] to obtain homozygous AsDUF538 overexpressing $(\mathrm{OE})$ lines at $\mathrm{T} 2$ generation for further assays and analyses.

\subsection{Morphological Analysis of Arabidopsis OE Lines}

To verify the occurrence of morphological alterations in root development and leaf surfaces of transgenic plants overexpressing AsDUF538, samples were collected from four-week-old Arabidopsis WT plants and two OE lines (OE4 and 8). Root and leaf morphology were observed using the fluorescence mode bright and dark field in the microscope AxioPhot, and images captured as described above.

\subsection{Arabidopsis OE Lines Inoculation with Meloidogyne incognita}

Ten Arabidopsis WT plants and three independent OE lines (OE4; 8; and 17) grown on a sand:substrate mixture $(2: 1 ; v: v)$ for three weeks were inoculated with approximately $2000 \mathrm{~J} 2$ of M. incognita, as previously described by [42]. Roots were then collected at 60 DAI, individually weighted and stained with acid fuchsin. The nematode infection was assessed by counting the number of females in each plant root system in the fluorescence stereomicroscope. The number of nematode females per gram of roots in WT plants and OE lines was determined and statistically compared using the $t$-test $(p<0.05)$, according to [42].

\subsection{Gene Expression Analysis of Arabidopsis OE Lines}

Total RNA was extracted from T2 seedlings of Arabidopsis OE lines and WT plants by RNeasy Plant Mini kit (Qiagen, Hilden, Germany) and reverse transcription was conducted for cDNA synthesis, as previously described [23]. RT-PCR analysis of 24 stress-related Arabidopsis marker genes (Supplementary Table S1) was performed according to [23].

The relative expression of the AsDUF538 transgene and five stress-related Arabidopsis marker genes was determined in OE lines and WT plants through qRT-PCR analysis using specific primers (Supplementary Table S2), as previously described [42]. The qRT-PCR reactions were conducted on a StepOne Plus Real-Time PCR System (Applied Biosystems, Foster City, CA, USA), as previously described [23], using biological and technical triplicates for WT plants and each OE line. No template control (NTC) samples were included as negative controls. qRT-PCR cycling consisted of four steps: $50{ }^{\circ} \mathrm{C}$ for $2 \mathrm{~min} ; 95^{\circ} \mathrm{C}$ for $10 \mathrm{~min}$; followed by 40 cycles of $95^{\circ} \mathrm{C}$ for $15 \mathrm{~s}$ and $60^{\circ} \mathrm{C}$ for $1 \mathrm{~min}$, and a final dissociation curve step of at $95^{\circ} \mathrm{C}$ for $15 \mathrm{~s}, 60^{\circ} \mathrm{C}$ for $60 \mathrm{~min}$ and $95^{\circ} \mathrm{C}$ for $15 \mathrm{~s}$. The online real-time PCR Miner tool [43] was used to estimate the primer efficiency and optimal cycle of quantification $(\mathrm{Cq})$ values.

The mean normalized expression (MNE) of AsDUF538 transgene in OE lines, relative to the AtACT2 reference gene (Supplementary Table S2), was calculated using the Q-GENE software (http:/ / www.gene-quantification.de/ download.html; accessed on 25 November 2020) [44]. The quantification of mRNA levels of the five Arabidopsis marker genes in OE lines, relative to WT plants were calculated and statistically tested via REST 2009 v. 2.0.13 software [45], using AtACT2 and AtEF-1 $\alpha$ as the reference genes (Supplementary Table S2).

\section{Results}

\subsection{Molecular Characterization and Cloning of AsDUF538}

The consensus coding sequence of the DUF538 gene from A. stenosperma (AsDUF538) was determined by the alignment of eight Arachis sequences putatively coding for DUF538 proteins, using as reference an $A$. stenosperma sequence (Genbank EH045758.1) previously identified as upregulated in RKN-infected roots [21] (Figure 1A). Five aligned sequences were obtained from public databases, such as NCBI (XM_025756132; XM_016080842; and XM_016329625) and PeanutBase (Araip.IZQ8N and Arahy.E28A1S) and two (259_c3148 
and large_rep_c660) from SRA NCBI database (Bio Project PRJNA284674). They comprised transcript sequences from distinct Arachis wild species, A. stenosperma (Araste), A. duranensis (Aradu), and A. ipaënsis (Araip), and from the cultivated species A. hypogaea (Arahy). The $414 \mathrm{bp}$ consensus coding sequence of AsDUF538 produced from the alignment of these eight sequences (Figure 1A) showed high nucleotide conservation, with the in-frame stop codon (TAA) at position 414, relative to the start codon (ATG) at position 1 (Figure 1A). Only two single nucleotide polymorphisms (SNPs) were identified at positions 273 (T:A) and 285 (G:A).

AsDUF538 encodes a putative protein of 137 amino acid residues, with a unique DUF538 conserved domain (PF04398), and a theoretical pI of 9.12 and molecular weight of $15.18 \mathrm{kDa}$ (Figure 1B). No signal peptide was identified in this amino acid sequence. To show the high conservation among the DUF538 superfamily among legume species, we performed a phylogenetic analysis using the plant species at Uniprot (https: / / www. uniprot.org/; accessed on 5 August 2020), with the highest level of identity with AsDUF538 (Figure 1C).

\subsection{AsDUF538 Transcripts in Arachis Roots Inoculated with Meloidogyne arenaria}

The temporal and spatial in situ distribution of AsDUF538 transcripts was determined on semi-thin sections of roots and leaves of $A$. stenosperma, the RKN-resistant species and $A$. hypogaea, the susceptible species. Roots of $A$. stenosperma collected at 3 DAI with $M$. arenaria showed hybridization signals in few radicular cells (Figure 2A,B), mainly concentrated in cells of the vascular cylinder (xylem, phloem, and intervening procambial or cambial cells). These same cells showed stronger hybridization in A. stenosperma roots at 6 DAI (Figure 2C). On the contrary, root sections of A. hypogaea collected at 3 DAI lacked detectable signals (Figure 2D,E), but with some signals detected in the vascular cylinder cells at 6 DAI (Figure 2F). These results indicated an earlier and stronger in situ hybridization of the AsDUF538 probe in A. stenosperma than in A. hypogaea, suggesting that the accumulation of transcripts occurs differently in the susceptible and resistant Arachis species.

Interestingly, mock-inoculated roots of both Arachis species hybridized with the antisense probe (SP6) lacked hybridization signals in their roots collected six days after the start of the bioassay, as demonstrated by the root section of A. stenosperma (Figure 2G). Likewise, roots collected at 6 DAI, from both Arachis species that were hybridized with the sense probe (T7) lacked signals, as demonstrated by the root section of $A$. hypogaea (Figure 2H).

Leaves from inoculated $A$. stenosperma plants collected at 6 DAI showed evident hybridization signals in the vascular cylinder cells (Figure 2I-K), which lacked in the cells of A. hypogaea leaves (Figure 2L,M). 


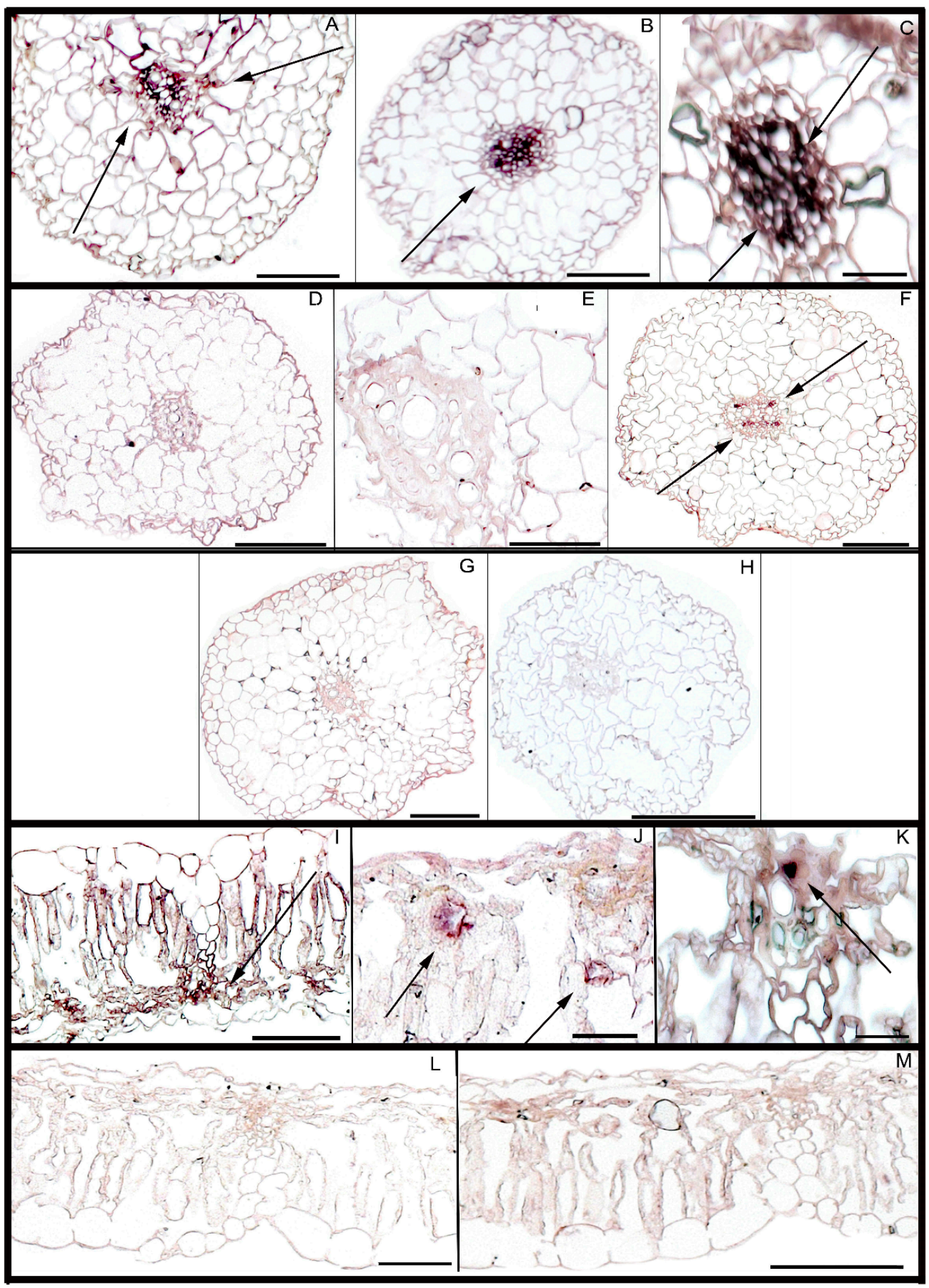

Figure 2. In situ distribution of AsDUF538 transcripts in Arachis spp. In situ spatial and temporal distribution of AsDUF538 transcripts in semi-thin plastic sections of roots and leaves of $A$. stenosperma and A. hypogaea plants inoculated, or not, with $M$. arenaria J2. In situ hybridization evident signals (dark purple) in cells of the vascular cylinder (arrows) of (A,B) A. stenosperma at 3 DAI and (C) 6 DAI, but lacking $(\mathbf{D}, \mathbf{E})$ in A. hypogaea 3 DAI, with some transcripts detected at 6 DAI (F). No signals were observed in roots of mock-inoculated plants for both species, as demonstrated (G) by A. stenosperma at six days after start of the bioassay. No signal was observed with the control sense probe (T7) in root sections of both species, as demonstrated (H) by the root section of A. hypogaea at 6 DAI. In situ hybridization in sections of leaves (I-K) from inoculated A. stenosperma plants at $6 \mathrm{DAI}$, with signals present in different cells, mostly concentrated in the cells of the vascular cylinder (arrows), whilst in (L,M) A. hypogaea plants, leaves lacked signal detection. Bars = $100 \mu \mathrm{m}(\mathbf{B}, \mathbf{H}, \mathbf{K}, \mathbf{L}) ; 50 \mu \mathrm{m}(\mathbf{A}, \mathbf{D}, \mathbf{F}, \mathbf{G}, \mathbf{H}) ; 20 \mu \mathrm{m}$ (C,E,J) and $10 \mu \mathrm{m}(\mathbf{I})$. 


\subsection{Meloidogyne arenaria Infection in Peanut Hairy Roots}

After 20 days of $A$. rhizogenes transformation, roots emerging from the petiole-wounding site of peanut detached leaves (Figure $3 \mathrm{~A}$ ) were analyzed for the presence of GFP fluorescence (Figure 3B). From the 20 detached leaves transformed with the pPZP-empty vector, $18(90 \%)$ developed eGFP-positive hairy roots, with an average of six hairy roots per leaf. Likewise, from the 20 detached leaves transformed with pPZP-AsDUF538, $16(80 \%)$ were positively transformed, with the same average number of six hairy roots per leaf. All eGFP-positive roots transformed with both vectors exhibited typical hairy root phenotype, including vigorous growth and extensive lateral branches (Figure 3A). These results indicated that the efficiency of $A$. rhizogenes transformation and induction of hairy roots per detached leaf were not affected by AsDUF538 overexpression.

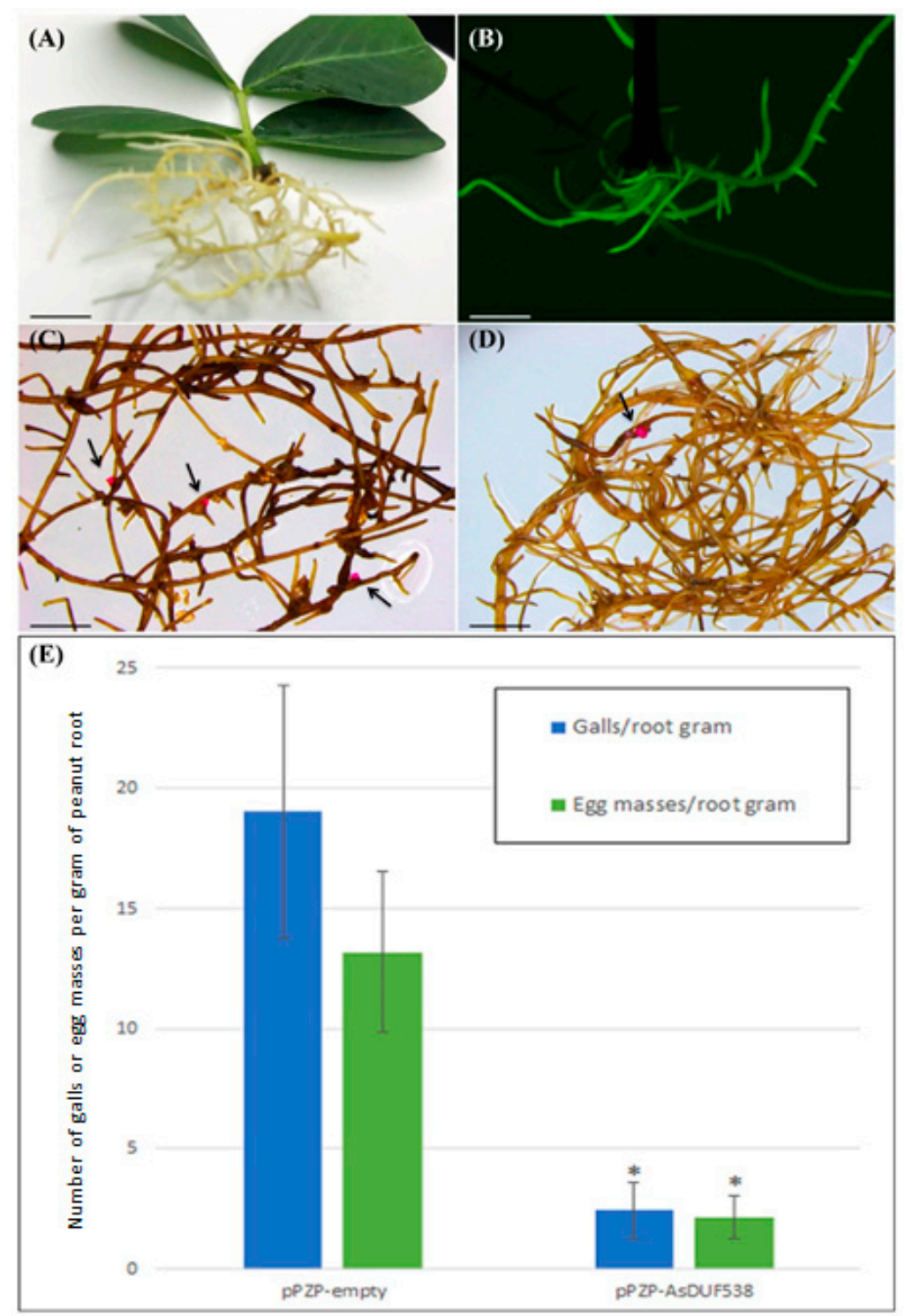

Figure 3. Meloidogyne arenaria infection analysis in peanut hairy roots. Transgenic peanut hairy roots transformed with pPZP-empty observed in the stereomicroscope using (A) bright field and (B) epifluorescence. Transgenic peanut hairy roots transformed with (C) pPZP-empty and (D) pPZPAsDUF538 at 60 days after M. arenaria inoculation. Arrows indicate egg masses. (E) Mean number of galls and egg masses per gram of root ( \pm standard deviation) in peanut hairy roots transformed with pPZP-empty and pPZP-AsDUF538. Statistical analyses were performed using the $t$-test and asterisks indicate significant differences $(p<0.05)$. Bars $=5 \mathrm{~mm}$. 
Sixty days after $M$. arenaria inoculation, 10 detached leaves transformed with the pPZP-empty and 10 with pPZP-AsDUF538 vectors (55 and 62\%, respectively), displaying GFP fluorescence, were considered for nematode infection assessment. Since each detached leaf produced an average of six hairy roots, approximately 60 roots were thus evaluated per treatment (pPZP-empty and pPZP-AsDUF538 transformation). eGFP-positive hairy roots showed average biomass of 232 and $276 \mathrm{mg}$ per detached leaf transformed with pPZP-AsDUF538 and pPZP-empty vectors, respectively. The root biomass for the above treatments did not differ significantly $(p<0.01$; $t$-test) and was similar to our previous studies with hairy roots transformed with pPZP-empty vector or overexpressing distinct candidate genes $[33,37]$. The $M$. arenaria infection was assessed in eGFP-positive hairy roots derived from $\mathrm{pPZP}$-empty vector transformation by gall development (average of 19.03 galls per root gram) and production of egg masses (average 13.17 egg masses per root gram) (Figure 3C,E). This confirms the ability of $M$. arenaria to infect hairy roots derived from detached peanut leaves and successfully complete its life cycle inside these roots, as previously demonstrated [33,37]. The number of galls (average of 2.44 galls per root gram) and egg mass (average of $2.15 \mathrm{egg}$ masses per root gram) at $60 \mathrm{DAI}$ was drastically reduced in hairy roots derived from the pPZP-AsDUF538 vector in comparison to the control roots that did not express the transgene (Figure 3D,E). Therefore, the overexpression of AsDUF538 promoted a significant ( $p<0.05$; $t$-test) reduction of $87.18 \%$ in $M$. arenaria galls and $83.66 \%$ in the egg masses in peanut hairy roots.

\subsection{Meloidogyne javanica Infection in Soybean Hairy Roots}

Seven days after $A$. rhizogenes transformation, from the 40 soybean plantlets transformed with pPZP-empty vector and 40 with pPZP-AsDUF538, 28 (70\%) and 25 (62\%), respectively, developed typical hairy roots at the hypocotyl wounding site. The subsequent screening revealed that around $60 \%$ of the induced hairy roots per composite plant exhibited GFP fluorescence. As observed for peanut hairy roots, these results indicated that the efficiency of $A$. rhizogenes transformation and induction of hairy roots in composite soybean plants were not affected by the overexpression of AsDUF538.

At 60 days after $M$. javanica inoculation, soybean showed hairy roots (Figure 4A) with GFP fluorescence (Figure 4A,B). From the 28 and 25 composite plants expressing pPZP-empty and pPZP-AsDUF538 vectors, 10 (55\%) and six (24\%), respectively, still showed eGFP-positive hairy roots at 60 DAI. Only roots showing GFP fluorescence were considered for nematode infection assessment. Regardless of the binary vector used for A. rhizogenes-mediated transformation, composite plants maintained an average of $60 \%$ eGFP-positive roots at $60 \mathrm{DAI}$ and similar root biomasses, with an average of $2.75 \mathrm{~g}$ and $2.63 \mathrm{~g}$ for pPZP-empty and pPZP-AsDUF538 vectors, respectively, which did not differ significantly $(p<0.01 ; t$-test). The average number of developed galls and egg masses per gram of pPZP-empty hairy roots (16.01 and 17.58, respectively) (Figure 4C-E) indicated that $M$. javanica could successfully complete its life cycle inside soybean hairy roots, as previously demonstrated [46]. In contrast, hairy roots transformed with pPZP-AsDUF538 vector showed a strong reduction in nematode infection, with an average of 2.13 galls and 2.48 egg masses per root gram (Figure 4A,B,E). Therefore, a significant ( $p<0.05$; $t$-test) reduction of $86.66 \%$ in $M$. javanica galls and $85.91 \%$ in egg mass was observed in soybean hairy roots overexpressing AsDUF538. These percentage reductions are remarkably like those for peanut hairy roots and clearly reinforces that AsDUF538 overexpression increases the resistance to RKN infection in legume species. 


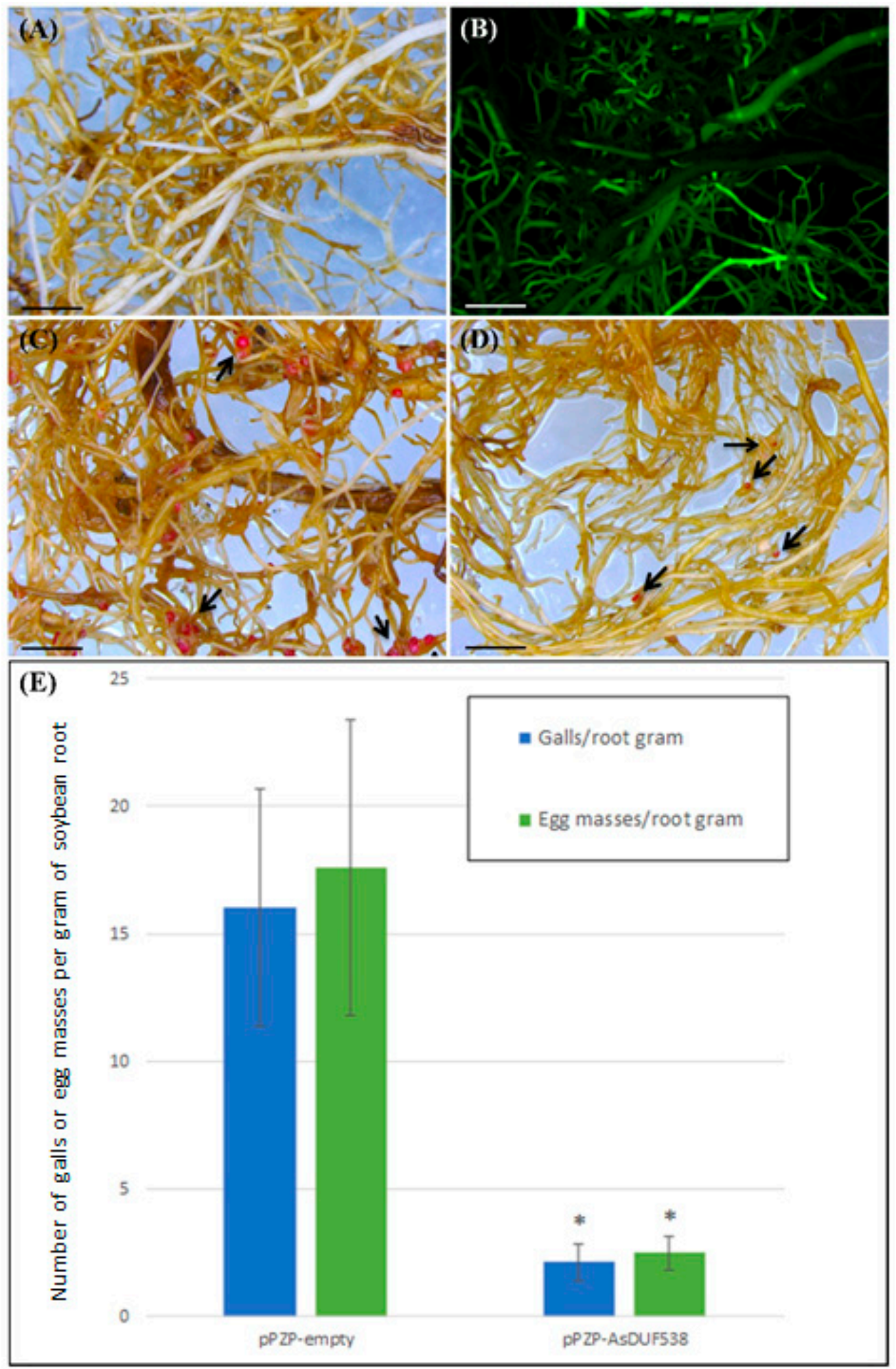

Figure 4. Meloidogyne javanica infection analysis in soybean hairy roots. Transgenic soybean hairy roots transformed with (A,B) pPZP-AsDUF538 and (C,D) pPZP-empty, 60 days after M. javanica inoculation, observed in the stereomicroscope using (B) epifluorescence and (A,B,D) bright field. Arrows indicate galls. (E) Mean number of galls and eggs masses per gram of root $( \pm$ Scheme 538 . Statistical analyses were performed using the $t$-test and asterisks indicate significant differences $(p<0.05)$. Bars $=5 \mathrm{~mm}$. 


\subsection{AsDUF538 Overexpression in Transgenic Arabidopsis}

In order to investigate the effects of AsDUF538 overexpression on M. incognita resistance, we further stably transformed Arabidopsis plants. A total of 15 independent homozygous $\mathrm{OE}$ lines at $\mathrm{T} 2$ generation was successfully obtained, and the overexpression of AsDUF538 transgene was subsequently confirmed in all OE lines by qRT-PCR analysis (Supplementary Figure S1). The AsDUF538 transcript abundance relative to the reference AtACT2 gene differed among individual OE line (Supplementary Figure S1), whilst its expression was not detected in WT plants. We selected three OE lines (OE4, 8, and 17) that displayed the highest AsDUF538 expression levels for further analysis.

Morphological analysis showed that developing roots and leaves of OE lines 4 and 8 had similar morphological characteristics compared to WT roots (Figure 5). OE lines displayed consistent cell and tissue morphology and organization in the different tissues of the roots and leaves, indicating that AsDUF538 overexpression did not affect the normal development and organization of these organs in Arabidopsis transgenic plants (Figure 5).
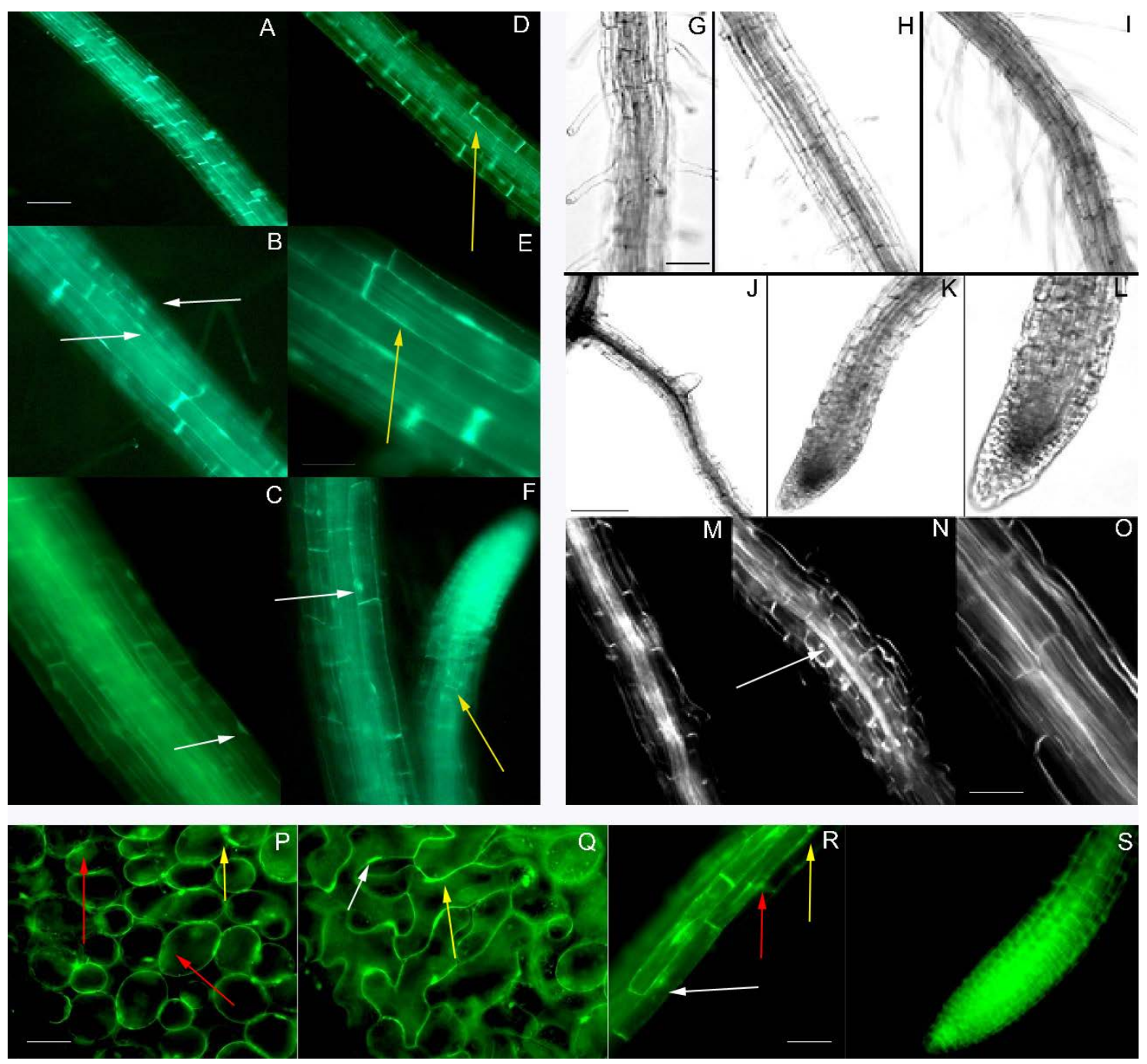

Figure 5. Root and leaf morphology in Arabidopsis OE lines and WT plants. (A-C) Roots from Arabidopsis OE lines 4 and (D-F) 8 showing green GFP fluorescence in the cell walls (yellow arrows), cytoplasm (red arrows) and nuclei (white arrows) of the epidermal root cells. Different regions of the roots from WT plants in bright field (G-L) and dark field (M-O) microscope modes. Leaf of the same plants of the OE lines (P) 4 and (R) 8 showing similar pattern between them and (Q,S) WT plants. Bars $=100 \mu \mathrm{m}(\mathbf{J}) ; 50 \mu \mathrm{m}(\mathbf{A}-\mathbf{D}, \mathbf{F}-\mathbf{I}, \mathbf{K}-\mathbf{N}, \mathbf{R}, \mathbf{S}) ; 20 \mu \mathrm{m}(\mathbf{E}, \mathbf{O})$ and $10 \mu \mathrm{m}(\mathbf{P}, \mathbf{Q})$. 


\subsection{Expression of Stress Related-Marker Genes in Arabidopsis OE Lines}

The expression of 24 stress-related genes in non-challenged Arabidopsis OE lines (OE4, 8 , and 17) and WT plants was analyzed by RT-PCR (Supplementary Table S1). As expected, the great majority of the stress-related genes analyzed, including an endogenous Arabidopsis DUF538 gene, were expressed in the OE lines and WT plants. In fact, expression of only two genes (AtAPX and AtHSFA2) was exclusively detected in transgenic plants, and one gene (AtSEB2.2) exclusively in WT plants. Together with the OE lines root and leaf morphological analysis (Figure 5), these results support the assumption that no pleiotropic effects are observed in transgenic AsDUF538 OE lines.

Considering the importance of jasmonic acid (JA) and ethylene (ET) signaling and ROS activation on defense responses against RKN infection, we investigated the expression behavior in the three OE lines of five Arabidopsis marker genes involved with these phytohormone pathways and the antioxidant defense system. This subset comprised genes coding for ascorbate peroxidase (AtAPX); transcription factor EIN3 (AtEIN3), jasmonate ZIM domain (AtJAZ1), allene oxide cyclase (AtAOC2), and helix-loop-helix DNA-binding family protein (AtMYC2) (Supplementary Table S2).

The AsDUF538 overexpression induced the expression of the five marker genes, given that their expression was higher in the OE lines than WT plants (Figure 6). As expected, the relative transcript abundance of each marker gene varied according to the transgenic line, regardless of its AsDUF538 transcript abundance (Supplementary Figure S1). A remarkable transcriptional induction of AtAPX and AtAOC2 genes was observed due to AsDUF538 overexpression, showing relative expression values above 56-fold for all OE lines (Figure 6A,B). Likewise, but to a lesser extent, AtJAZ1 was highly upregulated (>23-fold) in all OE lines (Figure 6C). The overexpression of AsDUF538 also lead to an increase in transcript levels of AtEIN3 (>8-fold) and AtMYC2 (>1.9-fold) (Figure 6D,E). These findings suggest that AsDUF538 may be involved in the regulation of JA and ET pathways, probably modulating the transcriptional dynamics of genes involved in their biosynthesis (AtAOC2), signaling (AtEIN3 and AtJAZ1), and cross-talk (AtMYC2), besides interplaying with the antioxidant defense system mediated by ROS scavengers (AtAPX).

\subsection{Arabidopsis OE Lines Infected with Meloidogyne incognita}

To evaluate the potential of AsDUF538 overexpression to confer RKN resistance, 10 individuals of each selected OE lines (OE 4; 8and 17) and 10 WT plants were challenged with M. incognita. Nematode infection was confirmed in Arabidopsis WT roots by the presence of typical RKN-susceptible symptoms, such as root galling and egg production. Conversely, the three OE lines were much less affected by $M$. incognita infection, showing significantly lower numbers of females per gram of roots (average of 617.8) when compared to WT roots (average of 1224.5) (Figure 7).

Overall, all three Arabidopsis OE lines showed a significant reduction in the number of RKN females per root gram at 60 DAI compared to WT plants ( $p<0.05 ;$-test). Whilst OE4 showed an average reduction of $42.4 \%$ and OE 8 of $45.7 \%$, the OE17 displayed the largest reduction of $50.1 \%$. These results suggested that AsDUF538 overexpression increases the ability of transgenic plants to mitigate damages caused by nematodes.

No visible differences in root and gall morphologies between WT and OE lines were observed at 60 DAI. Likewise, as observed for peanut and soybean hairy roots, roots from Arabidopsis WT plants and OE lines displayed similar biomass, ranging from 237.1 to $197.6 \mathrm{mg}$ of roots per plant, which did not differ significantly $(p<0.01 ; t$-test). These results corroborated our previous observation that AsDUF538 overexpression does not induce pleiotropic effects in transgenic plants. 

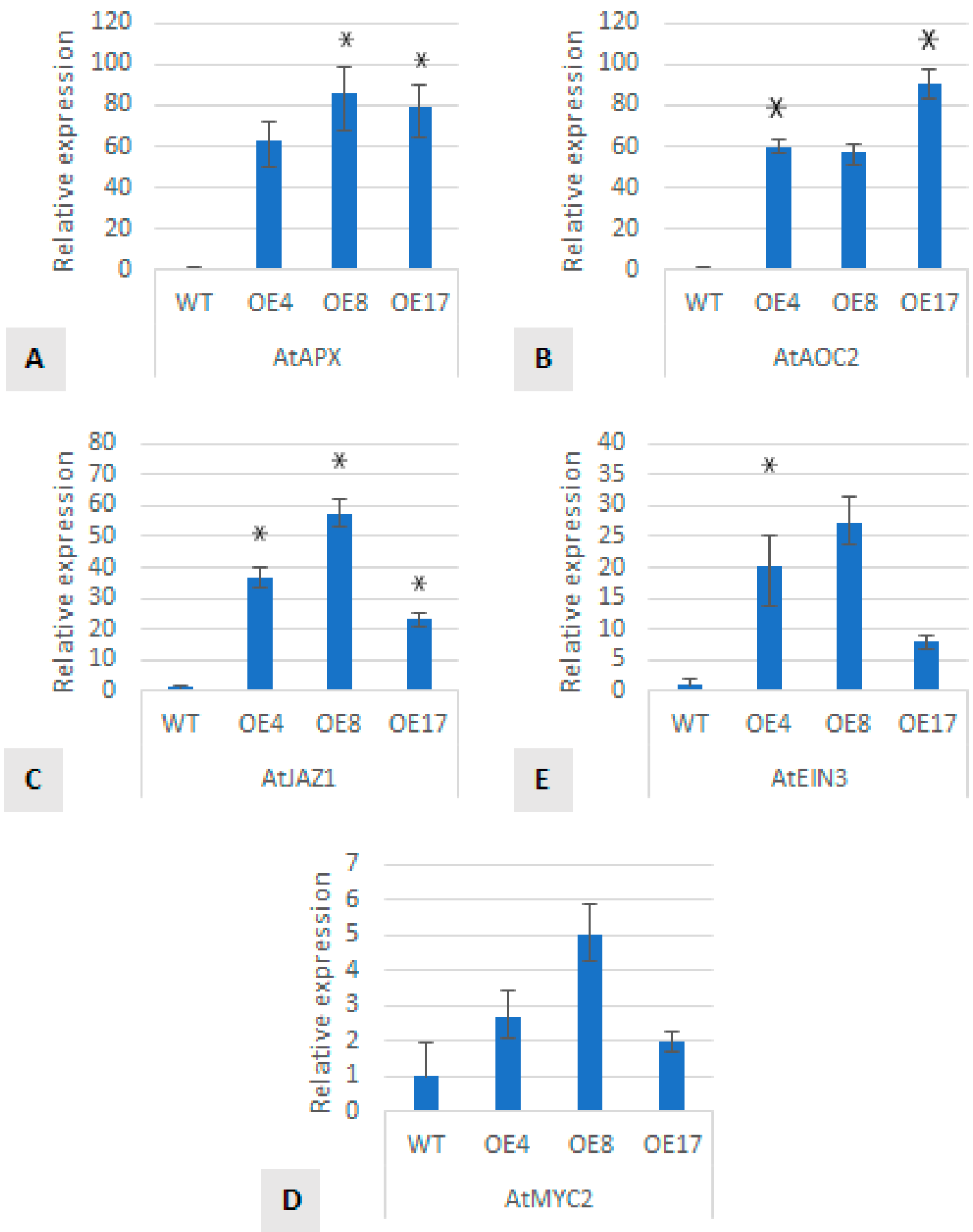

Figure 6. qRT-PCR analysis of marker genes in Arabidopsis OE lines. Relative quantification of mRNA levels of five Arabidopsis marker genes ((A) AtAPX; (B) AtAOC2; (C) AtJAZ1; (E) AtEIN3 and (D) AtMYC2) in the three OE lines (OE4, 8 and 17) relative to WT plants. Values are means \pm standard error of three biological replicates. Statistical analyses were performed using the $t$-test and asterisks indicate significant differences $(p<0.05)$. APX: ascorbate peroxidase; EIN3: transcription factor EIN3; JAZ1: jasmonate ZIM domain; AOC2: allene oxide cyclase 2; MYC2: helix-loop-helix DNA-binding family protein. 


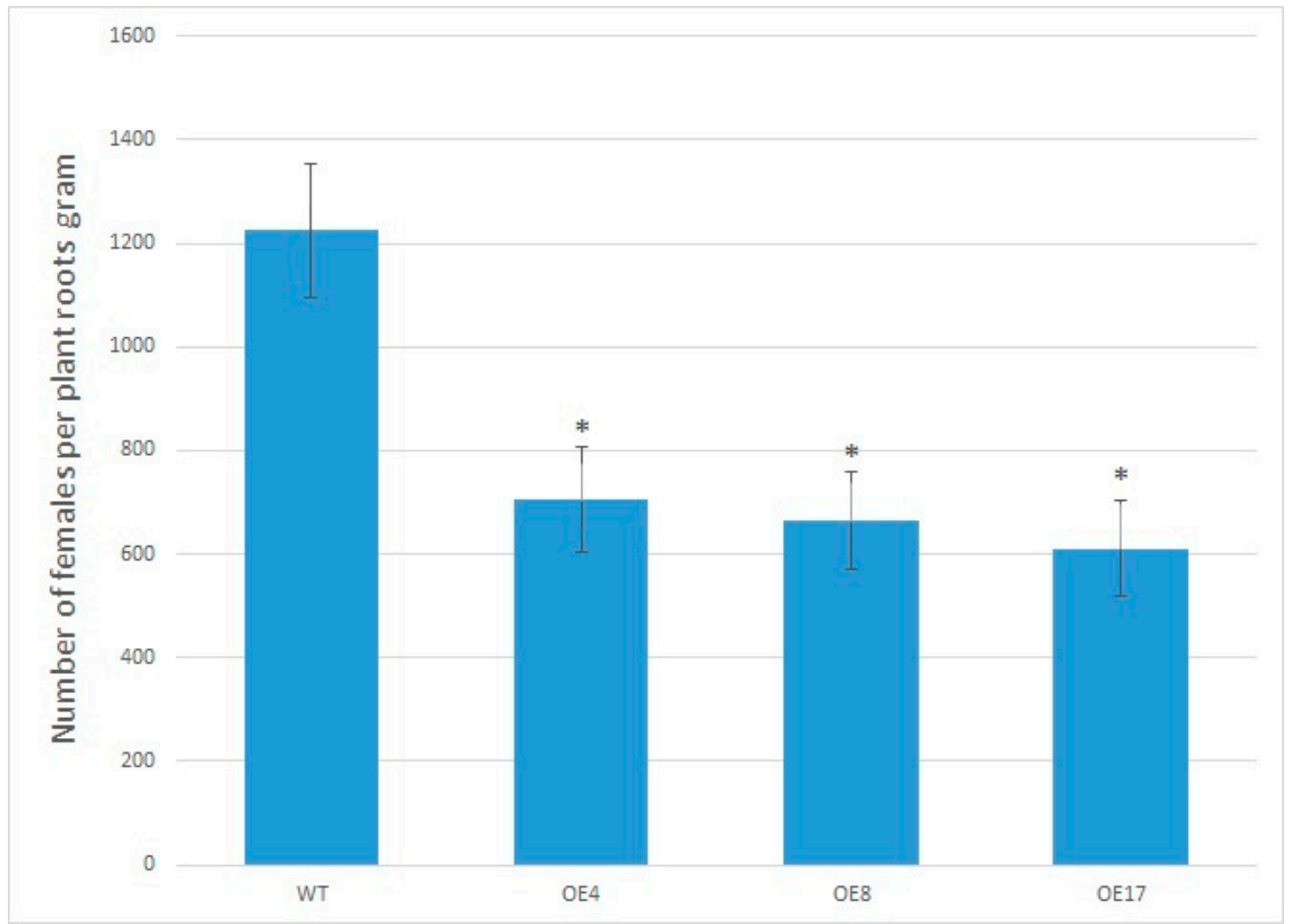

Figure 7. Meloidogyne incognita infection analysis in Arabidopsis OE lines. Average number of RKN females per plant roots of Arabidopsis WT plants and three OE lines (OE4, 8, and 17) at 60 days after inoculation with M. incognita. Values are means \pm standard error of 10 individuals. Statistical analyses were performed using $t$-test and asterisks indicate significant differences $(p<0.05)$.

\section{Discussion}

Novel proteins classified as DUF have been identified over the past years, particularly in the last decade, due to the addition of numerous transcriptome and proteome datasets, with more than 3961 proteins described in the Pfam database [47]. Within this group of hypothetical proteins, DUF538 have been identified as stress-responsive proteins in a wide range of mono and dicotyledonous plants, but little is known about their functional properties [28]. To our knowledge, this is the first time that DUF538 is functionally validated in planta and the first report of its overexpression conferring resistance to RKNs.

To date, DUF538-domain proteins have been associated to plant cell walls, thus being involved in cell elongation, division and modification and in defense responses to biotic and abiotic stress $[3,17]$. Additionally, studies on the structural/functional characterization of C. cristata protein containing a DUF538 domain suggest that it has a lipolytic enzymatic role [17]; contains a hydrolytic domain of the esterase type [27] and methylesterase activity towards pectin molecules [28]). However, despite various studies showing significant changes in DUF538 protein abundance and gene expression modulation during plant development and in response to different stresses [48], there is still a lack of in planta functional validation.

Our previous studies in wild Arachis species showed that AsDUF538 is typically induced in RKN-resistant $A$. stenosperma during its incompatible interaction with $M$. arenaria [21-23], suggesting a putative role for this gene in RKN defense responses. In the present study, in situ hybridization analysis using AsDUF538 as an RNA-labeled probe showed accumulation of AsDUF538 transcripts in roots of two Arachis species inoculated with $M$. arenaria, whilst hybridization was lacking in roots and leaves of non-inoculated 
plants. Therefore, these findings suggest that DUF538 expression in roots of $A$. stenosperma and $A$. hypogaea may depend on a stress stimulus, such as the presence of the RKN pathogen. This is in accordance with the A. hypogaea developmental transcriptome map [49], which indicated that DUF538 expression in plants showing normal development could only be detected at two different seed developmental stages (lateral stem leaf and reproductive shoot tip), with transcripts undetected in roots and leaves.

We also found that DUF538 transcripts observed in the vascular cylinder cells of the RKN-resistant species $A$. stenosperma accumulated more and at an earlier stage (3 DAI) than in the roots of the susceptible peanut (6 DAI). This earlier AsDUF538 transcript accumulation after RKN infection in the resistant, in comparison to the susceptible species, suggests that this defense response's timing is crucial, as observed for those involving ROS and hormonal signaling pathways [50]. It is known that signaling by different molecules can occur via xylem (transporter cells), as for those produced during fungi infection [51]; root bacteria symbiosis [52]; environmental stress [53]; abiotic stress [54]; ROS and electrical signals [55]. These transported molecules may play important functions to rapidly prompt initiation of defense responses and signal transduction to activate downstream transcriptional regulation. Therefore, the evident and earlier AsDUF538 expression in xylem cells of the resistant $A$. stenosperma is another indication of its involvement in plant defense responses against RKN infection.

In this work, we functionally validated AsDUF538 via its overexpression in RKNsusceptible genotypes of three different plant species (peanut, soybean, and Arabidopsis), with each transgenic system showing significantly improved resistance against its pathogen counterpart (M. arenaria, M. javanica, and M. incognita, respectively). This broad type of resistance suggests that AsDUF538 overexpression triggers early, non-specific, defense responses, such as those initiated by PTI (pathogen triggered responses), involving hormone signaling and molecules related to the maintenance of plant redox state in stressed plants, which in turn, regulates not only local but, also systemic plant defense responses (SAR) against pathogens [56].

This seems to be the case here, as the qRT-PCR expression analysis of stress-markers genes in Arabidopsis OE lines showed that an enzyme involved with JA biosynthesis, such as allene oxide cyclase (AtAOC2) [57] and the signaling protein jasmonate-ZIM domain (AtJAZ1) [58] were both strongly induced in the AsDUF538 OE lines. In addition, the transcription factor AtMYC2, which positively regulates JA-mediated resistance genes [59] was upregulated in the OE lines. Likewise, the ET signaling pathway seems to be induced in the OE lines due to a marked upregulation of the ET marker gene AtEIN3 (ethyleneinsensitive) [60,61]. The involvement of ET in this defense response is supported by previous reports showing that the overexpression of ET in Arabidopsis activates plant defense responses against the RKN M. graminicola in rice [62], whilst Arabidopsis plants overexpressing ET are less attractive to M. hapla juveniles [63].

In addition to hormone signaling, we also found that a gene coding for ascorbate peroxidase (AtAPX) was strongly upregulated in the Arabidopsis OE lines, suggesting that AsDUF538 could be linked to maintenance of the redox balance in stressed plants, as previously proposed by $[18,64]$. Therefore, our findings corroborate studies that suggest a role for DUF538 in a series of physiological and genetic adaptive responses, including balancing the uptake of ions in stress-challenged plants $[18,65]$. This could be due to its phosphorylation activity working as a potent activator of the redox system of plant cells, which in turn can lead to improved resistance against pathogen attack.

\section{Conclusions}

Plant hormones interact in complex networks to balance the response to developmental and environmental hazards to limit defense-associated fitness costs. Our results suggest that the overexpression of AsDUF538 in Arabidopsis leads to diverse defensive states in the plant, including the induction of hormone signaling pathways (JA and ET) and control of excessive ROS accumulation by antioxidant enzymes, which contribute 
to the improved RKN resistance. However, further integrated molecular, physiological, and agronomical studies are needed to assess the fitness costs associated with increased RKN resistance mediated by AsDUF538 overexpression in target plants. This is the first functional validation of a DUF538 gene and report of a DUF538 family member conferring resistance to Meloidogyne spp. This study also brings new insights into how DUF538 genes can trigger plant defense responses and provides a putative novel candidate gene for genetic engineering towards improved and more sustainable RKN resistant crops.

Supplementary Materials: The following are available online at https:/ / www.mdpi.com/2073-439 5/11/3/559/s1, Figure S1. Relative quantification of AsDUF538 expression in Arabidopsis OE lines. Relative quantification of AsDUF538 expression in 15 Arabidopsis OE lines using AtACT2 reference gene as normalizer. Table S1. RT-PCR analysis. Table S2. Primers used for qRT-PCR analysis.

Author Contributions: A.C.G.A., P.M.G., and A.C.M.B. contributed to the conception, design of the work, data analysis and interpretation, and drafting and critical revision of the manuscript. A.P.Z.M. conducted bioinformatics analysis, and critical revision of the manuscript; L.A.G., B.M.P., C.C.V., A.L.L. and A.C.Q.M. performed most of the data collection and analysis. All authors have read and agreed to the published version of the manuscript.

Funding: The authors acknowledge grants support from Empresa Brasileira de Pesquisa Agropecuária (Embrapa); Brazilian National Council for Scientific and Technological Development (CNPq); INCT PlantStress (project number 465480/2014-4); Coordination for the Improvement of Higher Education Personnel (CAPES) and FAPDF- Distrito Federal Research Foundation. Each of the funding bodies granted the funds based on a research proposal. They had no influence over the experimental design, data analysis or interpretation, or writing the manuscript.

Institutional Review Board Statement: Does not apply.

Informed Consent Statement: Does not apply.

Data Availability Statement: All the data used to support the findings of this study are included within this manuscript.

Acknowledgments: The authors would like to thank José F. M. Valls and Márcio Moretzsohn for supplying wild Arachis seeds; Regina M.D.G. Carneiro for providing nematode populations; Thaís N. Oliveira for helping with Arabidopsis analysis; and Mário A. S. Passos for valuable contributions to the RT-PCR and qRT-PCR experiments.

Conflicts of Interest: The authors declare that there is no conflict of interest regarding the publication of this paper.

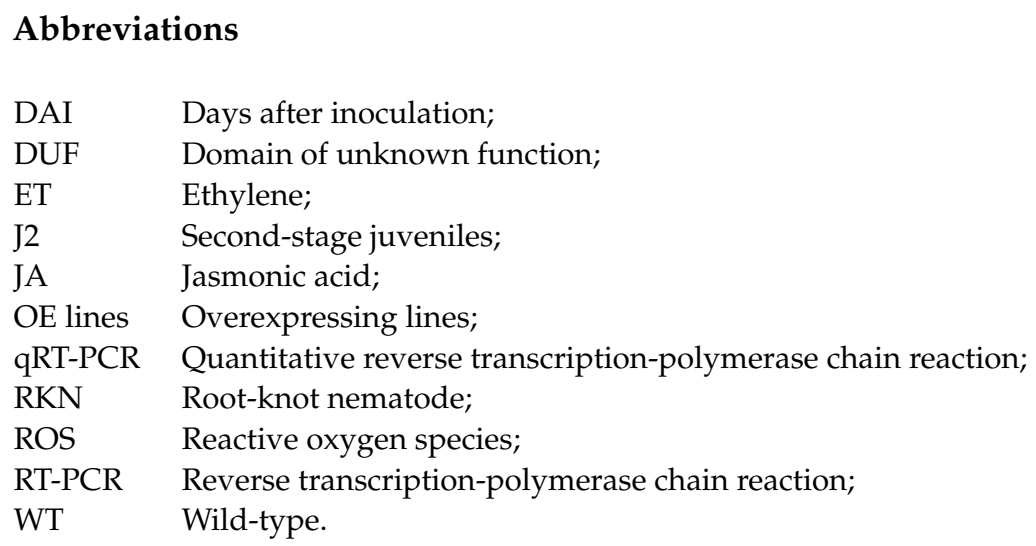

\section{References}

1. Li, L.; Xie, C.; Ye, T.; Xu, J.; Chen, R.; Gao, X.; Zhu, J.; Xu, Z. Molecular characterization, expression pattern and function analysis of the rice OsDUF866 family. Biotechnol. Biotechnol. Equip. 2017, 31, 243-249. [CrossRef]

2. Li, L.-H.; Lv, M.-M.; Li, X.; Ye, T.-Z.; He, X.; Rong, S.-H.; Dong, Y.-L.; Guan, Y.; Gao, X.-L.; Zhu, J.-Q.; et al. The Rice OsDUF810 Family: OsDUF810.7 May be Involved in the Tolerance to Salt and Drought. Mol. Biol. 2018, 52, 489-496. [CrossRef] 
3. Nabi, R.B.S.; Tayade, R.; Imran, Q.M.; Hussain, A.; Shahid, M.; Yun, B.-W. Functional Insight of Nitric-Oxide Induced DUF Genes in Arabidopsis thaliana. Front. Plant. Sci. 2020, 11, 1041. [CrossRef]

4. Takahashi, S.; Yoshikawa, M.; Kamada, A.; Ohtsuki, T.; Uchida, A.; Nakayama, K.; Satoh, H. The photoconvertible water-soluble chlorophyll-binding protein of Chenopodium album is a member of DUF538, a superfamily that distributes in Embryophyta. J. Plant. Physiol. 2013, 170, 1549-1552. [CrossRef] [PubMed]

5. Francin-Allami, M.; Merah, K.; Albenne, C.; Rogniaux, H.; Pavlović, M.; Lollier, V.; Sibout, R.; Guillon, F.; Jamet, E.; Larré, C. Cell wall proteomic of Brachypodium distachyon grains: A focus on cell wall remodeling proteins. Proteomics 2015, 15, 2296-2306. [CrossRef]

6. Nguyen-Kim, H.; Clemente, H.S.; Balliau, T.; Zivy, M.; Dunand, C.; Albenne, C.; Jamet, E. Arabidopsis thaliana root cell wall proteomics: Increasing the proteome coverage using a combinatorial peptide ligand library and description of unexpected Hyp in peroxidase amino acid sequences. Proteomics 2016, 16, 491-503. [CrossRef] [PubMed]

7. Mehdi, C.; Virginie, L.; Audrey, G.; Axelle, B.; Colette, L.; Hélène, R.; Elisabeth, J.; Fabienne, G.; Mathilde, F.-A. Cell Wall Proteome of Wheat Grain Endosperm and Outer Layers at Two Key Stages of Early Development. Int. J. Mol. Sci. 2019, 21, 239. [CrossRef]

8. Gholizadeh, A.; Kohnehrouz, B.B. Identification of DUF538 cDNA clone from Celosia cristata expressed sequences of nonstressed and stressed leaves. Russ. J. Plant. Physiol. 2010, 57, 247-252. [CrossRef]

9. Li, Y.F.; Wang, Y.; Tang, Y.; Kakani, V.G.; Mahalingam, R. Transcriptome analysis of heat stress response in switchgrass (Panicum virgatum L.). BMC Plant. Biol. 2013, 13, 1-12. [CrossRef]

10. Ajambang, W.; Volkaert, H.; Sudarsono, S. Carbohydrate deprivation upsurges the expression of genes responsible for programmed cell death in inflorescence tissues of oil palm (Elaeis guineensis Jacq.). Turk. J. Boil. 2016, 40, 1320-1327. [CrossRef]

11. Ding, C.; Chang, Z.; Wang, Y.; You, S.; Wang, S.; Ding, Y. Proteomic Analysis Reveals That Developing Leaves are More Sensitive to Nitrogen Fertilizer Than Mature Leaves. J. Plant. Growth Regul. 2017, 37, 426-437. [CrossRef]

12. Li, L.; Du, Y.; He, C.; Dietrich, C.R.; Li, J.; Ma, X.; Wang, R.; Liu, Q.; Liu, S.; Wang, G. A novel maize gene, glossy6 involved in epicuticular wax deposition and drought tolerance. BioRxiv 2018. BioRxiv:378687. [CrossRef]

13. Huang, Y.; Li, L.; Smith, K.P.; Muehlbauer, G.J. Differential transcriptomic responses to Fusarium graminearum infection in two barley quantitative trait loci associated with Fusarium head blight resistance. BMC Genom. 2016, 17, 1-16. [CrossRef] [PubMed]

14. Elagamey, E.; Sinha, A.; Narula, K.; Abdellatef, M.A.; Chakraborty, N.; Chakraborty, S. Molecular Dissection of Extracellular Matrix Proteome Reveals Discrete Mechanism RegulatingVerticillium DahliaeTriggered Vascular Wilt Disease in Potato. Proteomics 2017, 17, 1600373. [CrossRef] [PubMed]

15. Wang, M.; Weiberg, A.; Dellota Jr, E.; Yamane, D.; Jin, H. Botrytis small RNA Bc-siR37 suppresses plant defense genes by cross-kingdom RNAi. RNA Biol. 2017, 14, 421-428. [CrossRef]

16. Pan, Y.; Liu, Z.; Rocheleau, H.; Fauteux, F.; Wang, Y.; McCartney, C.; Ouellet, T. Transcriptome dynamics associated with resistance and susceptibility against fusarium head blight in four wheat genotypes. BMC Genom. 2018, 19, 1-26. [CrossRef]

17. Gholizadeh, A.; Kohnehrouz, S.B. DUF538 Protein Super Family is Predicted to be the Potential Homologue of Bactericidal/PermeabilityIncreasing Protein in Plant System. Protein J. 2013, 32, 163-171. [CrossRef]

18. Gholizadeh, A. Heterologous Expression of Stress-Responsive DUF538 Domain Containing Protein and its Morpho-Biochemical Consequences. Protein J. 2011, 30, 351-358. [CrossRef] [PubMed]

19. Gholizadeh, A. DUF538 protein superfamily is predicted to be chlorophyll hydrolyzing enzymes in plants. Physiol. Mol. Biol. Plants 2016, 22, 77-85. [CrossRef] [PubMed]

20. Prezelj, N.; Covington, E.; Roitsch, T.; Gruden, K.; Fragner, L.; Weckwerth, W.; Chersicola, M.; Vodopivec, M.; Dermastia, M. Metabolic consequences of infection of grapevine (Vitis vinifera L.) cv.“Modra frankinja” with Flavescence Dorée phytoplasma. Front. Plant. Sci. 2016, 7, 711. [CrossRef] [PubMed]

21. Proite, K.; Leal-Bertioli, S.C.M.; Bertioli, D.J.; Moretzsohn, M.C.; Da Silva, F.R.; Martins, N.F.; Guimarães, P.M. ESTs from a wild Arachis species for gene discovery and marker development. BMC Plant. Biol. 2007, 7, 1-10. [CrossRef]

22. Guimarães, P.M.; Brasileiro, A.C.M.; Proite, K.; De Araujo, A.C.G.; Leal-Bertioli, S.C.M.; Pic-Taylor, A.; Da Silva, F.R.; Morgante, C.V.; Ribeiro, S.D.G.; Bertioli, D.J. A Study of Gene Expression in the Nematode Resistant Wild Peanut Relative, Arachis stenosperma, in Response to Challenge with Meloidogyne arenaria. Trop. Plant. Biol. 2010, 3, 183-192. [CrossRef]

23. Morgante, C.V.; Brasileiro, A.C.M.M.; Roberts, P.A.; Guimaraes, L.A.; Araujo, A.C.G.G.; Fonseca, L.N.; Leal-Bertioli, S.C.M.M.; Bertioli, D.J.; Guimaraes, P.M. A survey of genes involved in Arachis stenosperma resistance to Meloidogyne arenaria race 1. Funct. Plant. Biol. 2013, 40, 1298-1309. [CrossRef]

24. Guimaraes, P.M.; Guimaraes, L.A.; Morgante, C.V.; Silva, O.B., Jr.; Araujo, A.C.G.; Martins, A.C.Q.; Saraiva, M.A.P.; Oliveira, T.N.; Togawa, R.C.; Leal-Bertioli, S.C.M.; et al. Root Transcriptome Analysis of Wild Peanut Reveals Candidate Genes for Nematode Resistance. PLoS ONE 2015, 10, e0140937. [CrossRef]

25. Mota, A.P.Z.; Vidigal, B.; Danchin, E.G.J.; Togawa, R.C.; Leal-Bertioli, S.C.M.; Bertioli, D.J.; Araujo, A.C.G.; Brasileiro, A.C.M.; Guimaraes, P.M. Comparative root transcriptome of wild Arachis reveals NBS-LRR genes related to nematode resistance. BMC Plant. Biol. 2018, 18, 1-16. [CrossRef] [PubMed]

26. Gholizadeh, A. Plants water soluble chlorophyll binding proteins act as enzyme-inhibitor pair. Russ. J. Plant. Physiol. 2017, 64, 91-99. [CrossRef]

27. Gholizadeh, A. Chlorophyll Binding Ability of Non-chloroplastic DUF538 Protein Superfamily in Plants. Proc. Natl. Acad. Sci. USA India Sect. B Boil. Sci. 2018, 88, 967-976. [CrossRef] 
28. Gholizadeh, A. Pectin methylesterase activity of plant DUF538 protein superfamily. Physiol. Mol. Biol. Plants 2020, 26, 829-839. [CrossRef] [PubMed]

29. Proite, K.; Carneiro, R.; Falcao, R.; Gomes, A.; Leal-Bertioli, S.; Guimaraes, P.; Bertioli, D.; Falcão, R.; Gomes, A. Post-infection development and histopathology of Meloidogyne arenaria race 1 on Arachis spp. Plant. Pathol. 2008, 57, 974-980. [CrossRef]

30. Guimaraes, P.M.; Brasileiro, A.C.M.; Mehta, A.; Araujo, A.C.G. Functional genomics in peanut wild relatives. In The Peanut Genome-Compendium of Plant Genomes; Varshney, R.K., Pandey, M.K., Puppala, N., Eds.; Springer: Berlin/Heidelberg, Germany, 2017; pp. 149-164.

31. Leal-Bertioli, S.C.M.; Moretzsohn, M.C.; Roberts, P.A.; Ballén-Taborda, C.; Borba, T.C.O.; Valdisser, P.A.; Vianello, R.P.; Araújo, A.C.G.; Guimarães, P.M.; Bertioli, D.J. Genetic Mapping of Resistance to Meloidogyne arenaria in Arachis stenosperma: A New Source of Nematode Resistance for Peanut. G3 Genes Genomes Genet. 2016, 6, 377-390. [CrossRef]

32. Ballén-Taborda, C.; Chu, Y.; Ozias-Akins, P.; Timper, P.; Holbrook, C.C.; Jackson, S.A.; Bertioli, D.J.; Leal-Bertioli, S.C.M. A new source of root-knot nematode resistance from Arachis stenosperma incorporated into allotetraploid peanut (Arachis hypogaea). Sci. Rep. 2019, 9, 1-13. [CrossRef]

33. Martins, A.C.; Mehta, A.; Murad, A.M.; Mota, A.P.; Saraiva, M.A.P.; Araújo, A.C.; Miller, R.N.; Brasileiro, A.C.; Guimarães, P.M. Proteomics unravels new candidate genes for Meloidogyne resistance in wild Arachis. J. Proteom. 2020, 217, 103690. [CrossRef] [PubMed]

34. Mota, A.P.Z.; Fernandez, D.; Arraes, F.B.M.; Petitot, A.-S.; De Melo, B.P.; De Sa, M.E.L.; Grynberg, P.; Saraiva, M.A.P.; Guimaraes, P.M.; Brasileiro, A.C.M.; et al. Evolutionarily conserved plant genes responsive to root-knot nematodes identified by comparative genomics. Mol. Genet. Genom. 2020, 295, 1063-1078. [CrossRef] [PubMed]

35. Kumar, S.; Stecher, G.; Li, M.; Knyaz, C.; Tamura, K. MEGA X: Molecular evolutionary genetics analysis across computing platforms. Mol. Biol. Evol. 2018, 35, 1547-1549. [CrossRef] [PubMed]

36. Chu, Y.; Guimarães, L.A.; Wu, C.L.; Timper, P.; Holbrook, C.C.; Ozias-Akins, P. A Technique to Study Meloidogyne arenaria Resistance in Agrobacterium rhizogenes-Transformed Peanut. Plant. Dis. 2014, 98, 1292-1299. [CrossRef]

37. Pereira, B.M.; Guimaraes, L.A.; Souza, N.O.S.; Saraiva, M.A.P.; Guimaraes, P.M.; Brasileiro, A.C.M. Overexpression of Wild Arachis Lipocalin Enhances Root-Knot Nematode Resistance in Peanut Hairy Roots. Plant. Mol. Biol. Rep. 2019, 37, 74-86. [CrossRef]

38. Guimaraes, L.A.; Pereira, B.M.; Araujo, A.C.G.; Guimaraes, P.M.; Brasileiro, A.C.M. Ex vitro hairy root induction in detached peanut leaves for plant-nematode interaction studies. Plant. Methods 2017, 13, 1-10. [CrossRef]

39. Kuma, K.M.; Lopes-Caitar, V.S.; Romero, C.C.T.; Silva, S.M.H.; Kuwahara, M.K.; Carvalho, M.; Abdelnoor, R.V.; Dias, W.P.; Marcelino-Guimarães, F.C. A high efficient protocol for soybean root transformation by Agrobacterium rhizogenes and most stable reference genes for RT-qPCR analysis. Plant. Cell Rep. 2015, 34, 1987-2000. [CrossRef]

40. Clough, S.J.; Bent, A.F. Floral dip: A simplified method forAgrobacterium-mediated transformation ofArabidopsis thaliana. Plant. J. 1998, 16, 735-743. [CrossRef]

41. Vinson, C.C.; Mota, A.P.Z.; Porto, B.N.; Oliveira, T.N.; Sampaio, I.; Lacerda, A.L.; Danchin, E.G.J.; Guimaraes, P.M.; Williams, T.C.R.; Brasileiro, A.C.M. Characterization of raffinose metabolism genes uncovers a wild Arachis galactinol synthase conferring tolerance to abiotic stresses. Sci. Rep. 2020, 10, 1-19. [CrossRef]

42. Mota, A.P.Z.; Oliveira, T.N.; Vinson, C.C.; Williams, T.C.R.; Costa, M.M.D.C.; Araujo, A.C.G.; Danchin, E.G.J.; Grossi-De-Sá, M.F.; Guimaraes, P.M.; Brasileiro, A.C.M. Contrasting Effects of Wild Arachis Dehydrin Under Abiotic and Biotic Stresses. Front. Plant. Sci. 2019, 10, 497. [CrossRef] [PubMed]

43. Zhao, S.; Fernald, R.D. Comprehensive Algorithm for Quantitative Real-Time Polymerase Chain Reaction. J. Comput. Biol. 2005, 12, 1047-1064. [CrossRef]

44. Simon, P. Q-Gene: Processing quantitative real-time RT-PCR data. Bioinform 2003, 19, 1439-1440. [CrossRef] [PubMed]

45. Pfaffl, M.W.; Horgan, G.W.; Dempfle, L. Relative expression software tool (REST) for group-wise comparison and statistical analysis of relative expression results in real-time PCR. Nucleic Acids Res. 2002, 30, e36. [CrossRef] [PubMed]

46. Guimaraes, L.A.; Mota, A.P.Z.; Araujo, A.C.G.; Figueiredo, L.F.D.A.; Pereira, B.M.; Saraiva, M.A.D.P.; Silva, R.B.; Danchin, E.G.J.; Guimaraes, P.M.; Brasileiro, A.C.M. Genome-wide analysis of expansin superfamily in wild Arachis discloses a stress-responsive expansin-like B gene. Plant. Mol. Biol. 2017, 94, 79-96. [CrossRef]

47. El-Gebali, S.; Mistry, J.; Bateman, A.; Eddy, S.R.; Luciani, A.; Potter, S.C.; Qureshi, M.; Richardson, L.J.; Salazar, G.A.; Smart, A. The Pfam protein families database in 2019. Nucleic Acids Res. 2019, 47, D427-D432. [CrossRef] [PubMed]

48. Bateman, A.; Coggill, P.; Finn, R.D. DUFs: Families in search of function. Acta Crystallogr. Sect. F Struct. Biol. Cryst. Commun. 2010, 66, 1148-1152. [CrossRef] [PubMed]

49. Clevenger, J.P.; Chu, Y.; Scheffler, B.; Ozias-Akins, P. A Developmental Transcriptome Map for Allotetraploid Arachis hypogaea. Front. Plant. Sci. 2016, 7, 1446. [CrossRef]

50. Camejo, D.; Guzmán-Cedeño, Á.; Moreno, A. Reactive oxygen species, essential molecules, during plant-pathogen interactions. Plant. Physiol. Biochem. 2016, 103, 10-23. [CrossRef] [PubMed]

51. Lin, T.-C.; Wang, P.-H.; Lin, W.-R. Changes of mycorrhizal fungal community occurring during the natural restoration after the chi-chi earthquake in Taiwan. Symbiosis 2018, 77, 177-184. [CrossRef]

52. Subramanian, S.; Cho, U.H.; Keyes, C.; Yu, O. Distinct changes in soybean xylem sap proteome in response to pathogenic and symbiotic microbe interactions. BMC Plant Biol. 2009, 9, 1-11. [CrossRef] [PubMed] 
53. Notaguchi, M.; Okamoto, S. Dynamics of long-distance signaling via plant vascular tissues. Front. Plant. Sci. 2015, 6, 161. [CrossRef] [PubMed]

54. Kuromori, T.; Seo, M.; Shinozaki, K. ABA Transport and Plant Water Stress Responses. Trends Plant. Sci. 2018, $23,513-522$. [CrossRef]

55. Choi, W.-G.; Miller, G.; Wallace, I.; Harper, J.; Mittler, R.; Gilroy, S. Orchestrating rapid long-distance signaling in plants with $\mathrm{Ca}^{2+}, \mathrm{ROS}$ and electrical signals. Plant. J. 2017, 90, 698-707. [CrossRef]

56. Xia, X.-J.; Zhou, Y.-H.; Shi, K.; Zhou, J.; Foyer, C.H.; Yu, J.-Q. Interplay between reactive oxygen species and hormones in the control of plant development and stress tolerance. J. Exp. Bot. 2015, 66, 2839-2856. [CrossRef]

57. Stenzel, I.; Hause, B.; Miersch, O.; Kurz, T.; Maucher, H.; Weichert, H.; Ziegler, J.; Feussner, I.; Wasternack, C. Jasmonate biosynthesis and the allene oxide cyclase family of Arabidopsis thaliana. Plant. Mol. Biol. 2003, 51, 895-911. [CrossRef]

58. Pauwels, L.; Goossens, A. The JAZ Proteins: A Crucial Interface in the Jasmonate Signaling Cascade. Plant. Cell 2011, 23, 3089-3100. [CrossRef]

59. Dombrecht, B.; Xue, G.P.; Sprague, S.J.; Kirkegaard, J.A.; Ross, J.J.; Reid, J.B.; Fitt, G.P.; Sewelam, N.; Schenk, P.M.; Manners, J.M.; et al. MYC2 Differentially Modulates Diverse Jasmonate-Dependent Functions in Arabidopsis. Plant. Cell 2007, 19, 2225-2245. [CrossRef]

60. Chao, Q.; Rothenberg, M.; Solano, R.; Roman, G.; Terzaghi, W.; Eckert, J.R. Activation of the Ethylene Gas Response Pathway in Arabidopsis by the Nuclear Protein Ethylene-Insensitive3 and Related Proteins. Cell 1997, 89, 1133-1144. [CrossRef]

61. Mur, L.A.J.; Prats, E.; Pierre, S.; Hall, M.A.; Hebelstrup, K.H. Integrating nitric oxide into salicylic acid and jasmonic acid/ ethylene plant defense pathways. Front. Plant. Sci. 2013, 4, 215. [CrossRef] [PubMed]

62. Nahar, K.; Kyndt, T.; De Vleesschauwer, D.; Höfte, M.; Gheysen, G. The Jasmonate Pathway Is a Key Player in Systemically Induced Defense against Root Knot Nematodes in Rice. Plant. Physiol. 2011, 157, 305-316. [CrossRef]

63. Fudali, S.L.; Wang, C.; Williamson, V.M. Ethylene Signaling Pathway Modulates Attractiveness of Host Roots to the Root-Knot Nematode Meloidogyne hapla. Mol. Plant.-Microb. Interact. 2013, 26, 75-86. [CrossRef] [PubMed]

64. Gholizadeh, A. Maltose-binding protein switches programmed cell death in Nicotiana glutinosa leaf cells. Cytol. Genet. 2014, 48, 85-91. [CrossRef]

65. Nakagami, H.; Sugiyama, N.; Mochida, K.; Daudi, A.; Yoshida, Y.; Toyoda, T.; Tomita, M.; Ishihama, Y.; Shirasu, K. Large-Scale Comparative Phosphoproteomics Identifies Conserved Phosphorylation Sites in Plants. Plant. Physiol. 2010, 153, 1161-1174. [CrossRef] [PubMed] 